Peer-Reviewed Article

ISSN: 2162-3104 Print/ ISSN: 2166-3750 Online

Volume 7, Issue 4 (2017), pp. 1010-1029

(C) Journal of International Students

http://jistudents.org/

doi: 10.5281/zenodo. 1035955

\title{
Exploring the Influence of Student Affairs on Adjustment and Adaptation for Indonesian Graduate Students
}

\author{
David J. Nguyen \\ Ohio University, USA \\ Jay B. Larson \\ Michigan State University, USA
}

\begin{abstract}
This qualitative study explored the influence of student affairs on academic adjustment and adaptation for 10 Indonesian graduate students at a single campus. Semi-structured interviews explored student affairs' role in adaptation and transition to collegiate life in the United States. Analyses illuminated ways in which participants experienced disequilibrium attending U.S. institutions arising from pre-arrival constructed images of college life in the United States. Student affairs functional areas disrupted these stereotypes for students and devised strategies for Indonesian students to feel more welcomed and included. Study participants described the importance of culturally-relevant student organizations, inclusive environments, and religiously affiliated centers in their adjustment. The article concludes with practical implications for student affairs professionals and higher education institutions.
\end{abstract}

Keywords: adaptation, adjustment, graduate education, graduate student affairs, Indonesian students, international education, student affairs 
More than 1 million international students enrolled in a U.S. institution during academic year 2015-16 (Institute of International Education, 2016). Of these 1 million students, approximately $36.7 \%$ are pursuing graduate degrees. Students coming to the United States for graduate education need to adjust not only to the academic rigor expected, but also adapt to U.S. culture. Much of the research on international students has occurred on international undergraduate students (Lee, 2010; Lee \& Rice, 2007; Sherry, Thomas, \& Chui, 2010; Su \& Harrison, 2016). Few studies have considered these same challenges for international graduate students (Curtin, Stewart \& Ostrove, 2013). When international graduate students arrive on campus, they are often pushed towards assimilation of the host country's culture (Curtin et al., 2013; Pan \& Wong, 2011; Sherry et al., 2010). While a substantial body of research documents experiences of international students attending U.S. institutions (Mamiseishvili, 2011; Renn, Brazelton \& Holmes, 2014; Yan \& Berliner, 2010; Yao, 2014), many studies discuss international students as a homogenous classification regardless of diverse national origins (Poyrazli \& Grahame, 2007). However, country of origin likely plays a key role in how international students acculturate or experience connection to higher education institutions in the United States. Therefore, studies with international students need to be disaggregated by nationality (Hanassab \& Tidwell, 2002). To study Indonesian students as one nationality among many grouped under the terms "Asian" or "South Asian" seemingly ignores the life experiences, needs, and academic and social values that render Indonesian students distinct from other Asian international student populations. This study contributes to the extant literature through studying how student affairs professionals and programs foster adjustment and adaptation for Indonesian graduate students.

While many studies have illuminated negative experiences of undergraduate students, less is known about graduate students, particularly how Indonesian graduate students adjust and adapt to life in the United States (Bista, 2015; Erkan \& Walker, 2016; Hanassab \& Tidwell, 2002). The number of Indonesian students attending U.S. higher education institutions has continued to increase over the last six years; and the overall number of Indonesian students is almost one-half the total students attending U.S. institutions 20 years ago (Institute of International Education, 2016). According to the 2016 Open Doors report, 8,727 Indonesian students studied in the United States during the 2015/2016 academic year, an increase of $6.6 \%$ from the previous year, with $18.6 \%$ identified as post- 
baccalaureate degree seekers. Indonesian graduate students, like all graduate students, contribute to the financial and intellectual vitality of U.S. institutions (Andrade, 2008). To this end, Indonesian graduate students, like all students, should be supported both academically and socially.

International students face unique challenges, such as language barriers, different academic expectations, and a new place. Previous studies have documented how higher education institutions have created studentserving resources (e.g., international student centers, specific academic advisors, living learning communities) supporting the academic and social integration of undergraduate students, yet little is known about how student support functions foster connection for international graduate students. Furthermore, as institutions increase international student enrollments it is important to consider how Indonesian students adjust and adapt to life in the United States. Previous studies have demonstrated student affairs officials can play significant roles in international students' persistence and adjustment to educational pursuits in the United States (Mamiseishvili, 2011; Renn et al., 2014; Yan \& Berliner, 2010; Yao, 2014). This article explores how Indonesian graduate students utilize student affairs as a tool for adapting and adjusting to campus life.

\section{LITERATURE REVIEW}

In the last decade, Indonesian students' presence has grown in literature. However, authors often situate them within broad populations based on region (e.g., Arambewela, \& Hall, 2009; Bista, 2015; Collins, Sidhu, Lewis \& Yeoh, 2014; Poyrazli \& Grahame, 2007) or religion (e.g., Erkan \& Walker, 2016). Recent research has critiqued generalized perspectives (Mukminin \& McMahon, 2013; Yu \& Wright, 2016). For example, Mukminin, Yanto, and Yanto (2013) argued that embedding Indonesian student experiences within data on other Asian students obscures specific acculturation experiences of Indonesian students. Despite criticism, regional sampling continues, as in Bista's 2015 survey of Asian international students at 57 U.S. institutions, where the author used regional units of analysis without theoretical or analytical rationale.

Despite generalizations, Bista's (2015) work offers valuable analysis. The author made a definitive statement on student services rare in international student literature, asserting, "offices of international programs, resident life, student organizations, college departments, career centers, and student health centers are important" (p. 52) for international students. 
Ironically, in an earlier article, Bista and Foster (2011) argued, "Campus life issues such as athletics, activities, organizations, are not highly valued by international students" (p. 3) in comparison with academic and legal issues. Such dichotomy within the work of one author highlights the ambiguously defined role of student affairs in adjustment literature.

Other studies have embedded Indonesian students within multinational samples of Muslim students. For instance, in Erkan and Walker's 2016 study of Muslim students in Canada, the authors categorized international students as simply "non-Canadian" (p. 77). Despite limitations, such research could inform work on the Indonesian Muslim experience among international students. The most common themes in these studies were confronting attitudes towards Islam (Erkan \& Walker, 2016), daily prayer (Chen, Liu, Tsai \& Chen, 2015; Mukminin et al., 2013), access to Halal food (Chen et al., 2015; Mukminin et al., 2013), and comparatively liberal attitudes of domestic students (Chen et al., 2015). Chen and colleagues' 2015 study of Muslim Indonesian students in Taiwan presented a more focused perspective. For example, subjects found Taiwanese hosts more accommodating than those described in studies in Canada and the United States, with locals helping to arrange prayer spaces and locate Halal food.

Mukminin et al. (2013) also exclusively studied Indonesian students in research on religious adjustment at a U.S. institution. Unmentioned in much literature is the personal guilt, or feeling "bad and sinful" (Mukminin et al., 2013, p. 38), subjects reported when circumstances impeded religious practices. However, learners also avowed decreasing religious stress as they more capably navigated their new environments, and became more flexible in religious observance. Mukminin and McMahon (2013) turned to academic adjustment in an examination of 12 Indonesian doctoral students, reporting many issues found across international student adjustment literature. Among these were linguistic problems (Mukminin, 2012; Son \& Park, 2014; Yu \& Wright, 2016), relationships with faculty (Arambewela \& Hall, 2009; Yu \& Wright, 2016), and navigating discussion-based classes (Bista, 2015; Young \& Schartner, 2014). Mukminin et al. (2013) also found students academically unprepared by pre-departure experiences in Indonesia, particularly regarding demanding workloads of combined coursework and assistantships. Despite the authors' undeniable contributions, like many similar studies, their work fails to follow through with holistic syntheses of the Indonesian students' experiences, or description of specific processes in their adjustment. 
We situate our study within intersections and gaps among diverse theoretical, national, and cultural contexts. Current research provides a foundation of adjustment issues Indonesian students encounter when broad, and theoretical perspectives for framing their experiences are used. The need for this current study arises within the ill-defined areas of this literature. Demographically generalized samples of international students often lead to equally generalized findings obscuring experiences described in the following pages. Moreover, student services, particularly student affairs, are currently given cursory consideration at best. By addressing these areas, we can more completely understand adjustment experiences of Indonesian students at U.S. institutions.

\section{THEORETICAL FRAMEWORK}

We frame our analysis within Schartner and Young's (2016) Model of International Student Adjustment and Adaptation (Figure 1), which offers analytical elements supporting our focus on academic adjustment. As one of the few models developed explicitly for examining international student experiences, Schartner and Young's work facilitates methods and analysis integrating pre-arrival factors, distinctions between processes and outcomes, and the interplay of sociocultural, psychological, and academic adjustment.

In the model, adjustment processes begin with pre-arrival factors in students' home nations, allowing researchers to include analysis of motivations for studying abroad, and preconceptions regarding U.S. culture and academic life. Such factors present international students as complete individuals bringing an array of experiences to the home nation, rather than depict them as nationally or culturally homogenous archetypes.

Theoretical perspectives expressed in the model also render distinctions between adjustment as a set of processes, and adaptation as the behavioral outcomes of those processes (Matsumoto \& Hwang, 2013; Schartner \& Young, 2016; Young \& Schartner, 2014). This distinction is particularly valuable in highlighting complexities of adjustment processes, which can manifest in "self-esteem, self-awareness, physical health, selfconfidence, stress...dysfunctional communication, culture shock, depression, anxiety, diminished school and work performance, and difficulties in interpersonal relationships" (Matsumoto \& Hwang, 2013, p. 850).

Finally, interaction of psychological, sociocultural, and academic factors represented in the model's central Venn diagram, facilitates analysis 
of a holistic, integrated international student experience. Together, the elements discussed in this section comprise a theoretical framework that recognizes Indonesian students in our current study as individuals with rich personal histories and agency undertaking complex processes of adjustment in a U.S. institutional environment.

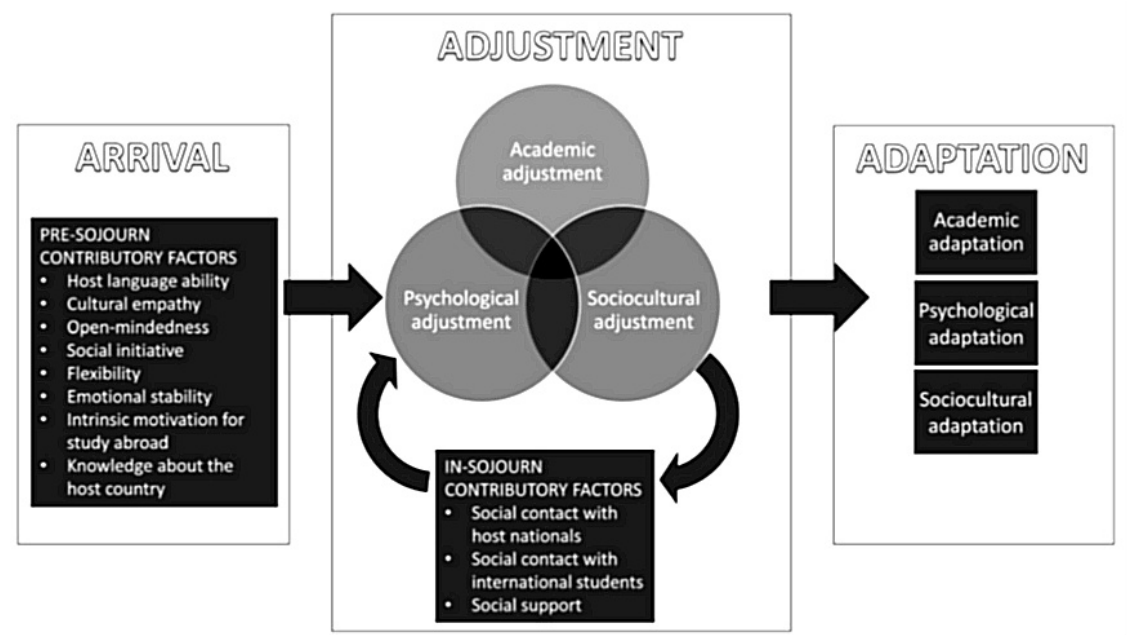

Figure 1. Schartner and Young's (2016) Model of International Student Adjustment and Adaptation. Reprinted with permission.

\section{RESEARCH METHOD}

This qualitative study explored the adjustment and adaptive experiences of Indonesian graduate students attending a large, public institution. More specifically, we employed narrative inquiry to create a space where the researcher can examine issues at both the local and specific level to reflect an individual's perspective on making sense of experience (Clandinin \& Connelly, 2000). Connelly and Clandinin (1990) cast narrative inquiry as both phenomenon and method, a combination deemed particularly useful in providing a venue for the voices of silenced and marginalized groups. Connelly and Clandinin (1990) positioned narrative inquiry as a methodology well suited for education by establishing its epistemological and ontological appropriateness for exploring lived educational experiences of students and teachers. Epistemologically, narrative inquiry holds the 
perspective that knowledge is constructed as individuals interact with each other, society, and their environments.

\section{Research Site}

The institution in this study holds a Carnegie classification as a doctoral research university with the highest research activity. This Midwestern U.S. institution enrolls over 50,000 undergraduate and graduate students from more than 130 countries. The institution defines international students as students lacking U.S. citizenship/permanent residency status or those requiring a visa to study in the United States. Fifteen percent of the institutional demography is classified as international students, constituting one of the largest international student populations in the United States. To support this burgeoning student population, the institution offers more than 20 internationally-focused offices and centers.

\section{Data Collection}

Before beginning the study, we received institutional review board approval. Participants were recruited using two methods to yield a purposeful sample (Patton, 2002). First, the researchers met with leaders from the institution's Indonesian student association. After meeting, the organization's president distributed a recruitment email and encouraged anyone interested to contact us directly. This recruitment effort yielded four participants. Second, at the conclusion of each interview, we asked participants to recommend other Indonesian graduate students who they thought might be interested. We received eight names, leading to interviews with six additional people.

Ten Indonesian graduate students participated in our study. At the time of the study, participant demographics included six men and four women; six doctoral and four masters' students, who were enrolled in education (5), science (3), technology (1), and public policy (1). All participant names have been replaced with pseudonyms. The researchers conducted an in-depth, semi-structured interview with each participant. Semi-structured interviews provide researchers with an interview guide composed of questions or areas for exploration, but also with the flexibility to follow up with participants to gain clarity and enhance understanding (Merriam, 2009). The interview protocol asked participants to share stories about their experiences of fostered or hindered adjustment and adaptation. In particular, we sought to understand how student affairs professionals and programs facilitated the transition period. Interviews ranged in time from 50 
to 98 minutes, with the average around 63 minutes. Each interview was audio recorded and transcribed verbatim.

\section{Data Analysis}

We analyzed data using Merriam's (2009) steps for data analysis. The authors read line-by-line through two transcripts independently and made notes about emerging patterns within the data (Merriam, 2009). After open coding, the researchers met to discuss emerging findings until no additional codes surfaced within the data, and then grouped codes into more specific and analytical categories (Corbin \& Strauss, 2008). Miles and Huberman (1994) referred to the limit of exhaustive coding as saturation. Analytical coding requires researchers to go beyond description, to also interpret and reflect on the meaning of the code. At this point, all interview transcripts were uploaded into Dedoose web-based qualitative software, and the analytical codes were applied to all transcripts. The emergent findings follow in a subsequent section.

We employed five steps to evaluate validity and reliability of processes yielding the conclusions in the next section. First, we triangulated results through multiple investigators being involved in the data analysis process (Merriam, 2009; Patton, 2002). Second, we used interrater reliability, as each researcher analyzed the data separately before meeting to peer debrief on emerging codes (Krippendorff, 2004). Also, the first author reviewed the second author's coding and vice versa to ensure consistent application of the coding scheme. Third, we employed member checks with key study participants to safeguard the interpretation of the quotes (Merriam, 2009). Fourth, we continued data collection until saturation occurred (Miles \& Huberman, 1994), as numerous participants shared similar stories of adaptation and adjustment. Finally, we kept an "audit trail" of key decisions made throughout the research process (Lincoln \& Guba, 1985).

\section{Limitations of Study Findings}

As is the case with all research studies, several limitations must be considered when interpreting findings. First, all participants had received some form of financial remuneration from a governmental or international funding agency. These students may differ from students funding their own education in the United States. Second, this study utilized cross-sectional data. Future research should consider a longitudinal design to capture more recent interactions with student affairs professionals. Third, all students 
were involved in some way with the Indonesian student association, so their experiences may not represent those of less involved students. Lastly, we acknowledge our positionality as outsiders to this specific student population, yet used key gatekeepers in introducing us to potential participants.

\section{RESULTS}

Student affairs functions supported Indonesian graduate students as they strove to adjust and adapt to demands of graduate education. Participant narratives expressed the disequilibrium many experienced while attending U.S. institutions. Before arriving in the United States, participants had constructed particular images of college life in the United States. Student affairs functional areas disrupted these stereotypes for students and devised strategies for Indonesian students to feel more welcomed and included. Study participants described the importance of culturally-relevant student organizations, inclusive environments, and religiously affiliated centers in their adjustment processes.

\section{Constructed Images and Culture Shock: Countering Pre-Arrival Understandings}

All students had preconceived images of how graduate education operated. Our participants discussed learning about college culture through media representations and through their funding sponsors. For example, Rafif (a pseudonym, as are all names used in this article) shared "I've kinda known what college life is like because I've been watching this movie called Animal House about fraternities...I learned a lot from the movie and like a bunch of other movies, like Old School and then National Lampoon." Like Rafif, many participants believed that their education would be filled with social activities depicted in such films in addition to academic responsibilities.

Through student affairs functions on their campus, participants engaged in social activities, if not of the Animal House variety. Daffa shared that through the International Scholars office he took part in "various activities that actually enable you to know much more about American culture, American family." He went on to describe how this led to other activities. "Something I really like that I never experienced before back in Indonesia was doing a lot of different kinds of volunteerism," Daffa said, 
"so a lot of volunteering activities on campus and also to the community." Like Daffa, other participants noted how student affairs functions provided them with welcomed social opportunities unlike those envisioned in their pre-arrival conceptions. For others, like Irene, these were welcome alternatives to the party-oriented activities that made her feel "awkward." Feeling more welcomed on-campus eased anxiety participants felt towards their education and encouraged them to engage more deeply with other students.

Seven students discussed participating in an international student orientation program. These orientation programs were designed to introduce students to the realities of U.S. graduate school and assist in lessening psychological tension about life in the United States. Nadya discussed learning about cultural nuances between Indonesia and the United States during orientation. For example, she described orientation as aiming to,

prepare us for the culture shock, the weather and some like general habit that people...do and don't...If you're like have an appointment, like if you are going to be late, then you have to inform that person that you will be late because people here, they're very, very, they value time. It's like very, very high - different with people in Indonesia. In Indonesia... if somebody invited you to go to his party like 5:00, then you will go like 6:00 or 6:30

Nadya's reflections demonstrated how many pre-arrival assumptions are not conscious preconceptions about the United States, but assumptions about the universality of their home-culture experiences. By developing an orientation to introduce new arrivals to the realities U.S. graduate life, their institution helped participants like Daffa and Nadya to stem "culture shock" through responsive, thoughtful programming and really begin to "fit in" on-campus during graduate education.

\section{Academics: Adjusting to Rigor and Adapting to Demands}

The primary reason students chose to leave Indonesia was to pursue a highly coveted credential from a U.S. institution. In making the preparations to attend graduate school in the United States, Dinda placed a significant emotional burden on herself. She shared,

It means a lot to me [to attend a U.S. graduate school] because, it will be very important for my career, so hopefully when I go back to Indonesia...the future will be right there for me. And also because U.S, specially for Indonesians...It's the best education that you can get nowadays here in the world. 
Participants largely agreed with Dinda's views on the career-advancing value in a degree from a U.S. institution. Accompanying academic pressure figured prominently into participants' adjustment stressors, as they described frustrations with the nature of academic programs.

A common aspect for which study participants felt unprepared was the change in how graduate academic programs utilized more discussion-based methods than traditional lectures. This shift led many participants to compare pedagogical practices in Indonesia and the United States. Indra specifically raised classroom dynamics as a salient difference between the two cultures:

[The classroom is] not going to be as stressful in Indonesia, and [in the U.S.] you have to be active...Indonesians like to be passive in class, and not because...they're not engaged or they don't know what's going on, but mainly because they're not confident because we're not used to...sharing our opinions, because our education system taught us to be more about just following instructions. You ask questions that have clear answers, but you don't ask questions, "What if?" But here, you do.

Like other participants, Daffa echoed Iwan's observations that in Indonesia, "students' contributions are not so encouraged in a sense of students' engagement in the process of teaching and learning." Daffa, however, eagerly anticipated this difference before arriving,

I would say my expectation then was to be in a classroom where everybody are so actively engaged in the conversation. And also like the professor and they have a very welcoming, safe environment for classroom discussion. So...when I came to the US, I really hoped that I can experience that.

Participants also mentioned other academic adjustments, such as Denny's lament of a primarily "U.S. focus in class material and discussion." Several participants also expressed shock at the workloads in their courses. As Nadya described,

One thing that really shook me is like the reading. We're not get used to like very, very much reading...There was a time when I have to read like more than 250 pages just for a week and just for one subject.

Some participants compartmentalized academic adjustments, rarely perceiving them as student affairs issues, and preferring to rely on social connections or advisors. As Rika explained, 
If it's more of a class [issue], I'd probably talk to like some of the students that are taking a similar class... or to my advisor. But yeah, I think international programs is more like if you have visa issues and stuff like that.

Although participants like Rika addressed adjustment by making selections from a perceived range of services and opportunities, they also viewed them as overlapping in their areas of support. In the following section, we demonstrate how Indonesian students found support for a range of adjustment issues among peers and organizations.

\section{Peers and Student Organizations Facilitate Adjustment and Adaptation}

Participants frequently described the importance of student organizations in providing places and space to connect with campus life, classes, and address specific international student issues. In particular, student organizations provided a sense of the familiar, while alleviating the homesickness experienced by many study participants. Nadya met peers through a student organization, and she shared that these peers encouraged her to,

try to experience as many things here as you can because if you're trying to, like, hold onto what you have back home, all you're gonna feel is homesick. And no matter how hard, how hard you try, this is a different country with a different culture and a different everything. You cannot recreate what you have in Indonesia here. Or I guess [you]'ll just have to adapt and keep an open mind. Just try to enjoy new experiences.

While uncomfortable at times, Nadya and a handful of participants embraced the challenge of adapting to a U.S. institution. But these students felt encouraged by peers in their student organizations to get involved. Rika's participation in student organizations allowed her to connect with other students outside the classroom in such activities as "hiking trips, skiing trips, sledding trips, [and] all the fun stuff." While many participants discussed lacking close relationships with domestic students, participants found community with the international student community. In particular, students discussed leveraging intramural sports as a way of connecting across other cultural boundaries. For example, one participant shared,

I interact with [other students through] the badminton club. We have [students] from China, from India, from U.S., from German[y] and from other countries...I interact with them in a badminton club 
outside the classroom. And also in volleyball, I have, like, lot of Turkish friend and also some U.S. friends."

Engaging with other students outside the classroom fostered a greater sense of connection to the campus and other students.

One student organization all study participants mentioned in some fashion was the Indonesian student organization present on campus. Many of the students held leadership roles in the organization at various times. Denny, who served as a president, used the annual cultural night as a way to showcase and expose the larger campus community to Indonesian culture. He shared,

I was like president of Indonesian student association and at the time, I held Indonesian cultural night and a lot of people coming at our events so I feel like, oh, [INSTITUTION] loves Indonesia and I invited like, I expected only 250 people coming but it was like more than 400 people coming.

A third type of student organization most participants discussed was religiously affiliated organizations. Faith played an important role in the lives of all participants. For some participants, they sought community through Muslim and Christian enclaves. Religion functioned as a gathering mechanism for students to form bonds.

\section{DISCUSSION}

The purpose of the current study was to explore how Indonesian graduate students utilize student affairs functions to facilitate adaptation and adjustment to their graduate institutions. This research makes a significant contribution to the literature through supporting findings from several studies about the experiences of international graduate students (Curtin et al., 2013). Our findings point to the distinctive, yet complex experiences Indonesian students have encountered on U.S. campuses. Many arrive on their campuses with particular constructions of what a college campus should look like (Hall, 1997; Nguyen, 2016; Shahjahan, Morgan \& Nguyen, 2015). Their ability to adjust and adapt to graduate education proved challenging, but also rewarding in perceived future pecuniary returns on education.

Study findings provide support for investigating student affairs functions' support for international students. Very little is known about the ways in which graduate students, especially international students, utilize 
student affairs resources. Traditionally, the sphere of influence for graduate students tends to be isolated within the graduate degree program or department (Austin, 2002; Gardner, 2010). Accordingly, findings from this study confirm existing research about Indonesian graduate students experiencing academic stressors (Mukinin, 2012; Zhang \& Goodson, 2011). In this study, academic challenges stemmed from the ways courses are organized compared to previous educational experiences in Indonesia. Participants adapted to this pedagogical approach, as their graduate programs operated differently than their previously conceived understandings of graduate education.

The student affairs offerings at the research site provided Indonesian graduate students with place and space to connect with other international and domestic students. While some participants expressed having homophilic friend groups, other participants realized the Indonesian population present on campus was limited. As such, they needed to look beyond national boundaries to connect with other international students. Student organizations offered through student affairs programs provided acculturative and adaptive experiences to life in the U.S. (Fries-Britt, George Mwangi, \& Peralta, 2014; Poyrazli, Arbona, Nora, McPherson \& Pisecco, 2002).

\section{IMPLICATIONS}

Our findings showed participants' reflections on adjustment processes to be rooted in their Indonesian backgrounds and identities, although many reflections also converged with experiences of other international students. Accordingly, we present implications for practice and scholarship that address Indonesian student experiences, but also afford applications for student affairs functions regarding all international college learners in a variety of institutional settings.

\section{Implications for Practice and Policy}

Participants in this study described disequilibrium occurring when pre-arrival understandings of U.S. college life did not match realities encountered upon arrival. Student affairs professionals can work with international student functional areas to provide admitted students with accurate, practical pre-arrival information. Professionals in host institutions can cultivate working relationships with those bodies in students' home nations that perform essential functions in sending students abroad, such as 
the funding bodies referenced by our participants. Through such relationships, these home-nation bodies can serve as conduits of reliable information, lessening disorienting conflicts between expectations and realities described by participants that can complicate adjustment and adaptation for Indonesian and other international students.

Student affairs professionals can also organize roundtable discussions in ways that simultaneously address academic and social issues of adjustment emergent in our data and findings. Participants often described difficult processes of adjusting to discussion-based learning in the classroom. Through programming in which Indonesian and other international student organizations facilitate discussions as part of social community-building events - perhaps in conjunction with a monthly potluck - students will have opportunities to engage in academic exchanges within a relaxed, non-threatening environment. When students carry newly developed confidence with expressing their own opinions and observations into the classroom, they can become vehicles for introducing Indonesian perspectives that participants found largely lacking in the U.S.-centered focus. Finally, these social roundtables can provide opportunities to merge their academic pursuits with the international student community that participants found a valuable source of support in their adjustment processes.

Specific programs and policies suggested here fall within overarching guidelines that professionals can implement across diverse institutional environments and their resources, organizational structures, and missions. Student affairs professionals can provide relevant information through myriad available means early in the pre-arrival phase of international students' experiences. Internal functions, such as recruitment and admissions, can provide such information should international working relationships prove unwieldy or unattainable. Programming that melds social and academic needs of international students can render adjustment a more manageably cohesive process. Writing workshops and coordinated participation or attendance at campus-wide academic events are only two possibilities for holistically meeting diverse adjustment needs of all international students. These guidelines can inform practices serving all phases of the international student experience. 


\section{Implications for Future Research}

We can further support practices for serving Indonesian students through continued research. Detailed nuance provided by participants in the current study illustrates the possibilities for further specialized research on adjustment experiences of Indonesian international students. We contend that highly focused studies on specified aspects of their experiences can counterbalance current literature in which authors frequently obscure Indonesian students within broad multi-national samples. We can support the work of practitioners by conducting intensive studies of Indonesian students' pre-arrival conceptions of U.S. college life. International student research often addresses cognitive dissonance following arrival, but little attention is given to their preconceptions before leaving home. Quantitative methods could prove useful for ascertaining the most common home-nation sources of information, while qualitative studies can present students' detailed descriptions of their preconceptions and the meanings attached to them. In doing so, we can gain better understanding of dissonance experienced by Indonesian students after arrival in the United States.

\section{CONCLUSION}

Schartner and Young's (2016) model of international student adjustment and adaptation provides a unique lens for understanding the experiences of Indonesian graduate students. In particular, this theoretical framing provides a richer understanding of international student experiences because the theory was developed with international students in mind. Pairing this theoretical orientation and qualitative framework contributes to the empirical literature about how Indonesian graduate students experience their adaptation and adjustment in the United States. Study findings continue to demonstrate Indonesian students experience academic and social challenges in their efforts to integrate into campus life (Mukminin, 2012). International students, including those from Indonesia, are called upon to make up the difference in support to declining state appropriations for postsecondary education (Cantwell, 2015). Student affairs professionals can play an important role in quelling the anxiety many Indonesian graduate students feel as they begin their academic journeys. 


\section{REFERENCES}

Andrade M. S. (2008). International graduate students: Adjusting to study in the United States. In K. A. Tokuno (Ed.), Graduate students in transition (pp. 71-88). Columbia, SC: University of South Carolina.

Arambewela, R., \& Hall, J. (2009). An empirical model of international student satisfaction. Asia Pacific Journal of Marketing and Logistics, 21(4), 555569.

Austin, A. E. (2002). Preparing the next generation of faculty: Graduate school as socialization to the academic career. Journal of Higher Education, 73(1), 94-122.

Bista, K. (2015). Asian international students' college experience: Relationship between quality of personal contact and gains in learning. Journal of International and Global Studies, 6(2), 39-54.

Bista, K. \& Foster, C. (2011). Issues of international student retention in American higher education. International Journal of Research and Review, 7(2), 110.

Chen, Y.-L., Liu, M.-C., Tsai, T.-W., \& Chen, Y.-H. (2015). Religious practices in cross-cultural contexts: Indonesian male science students' adjustment in Taiwan. Journal of Counseling Psychology, 62(3), 464-475.

Clandinin, D. J., \& Connelly, F. M. (2000). Narrative inquiry: Experience and story in qualitative research. San Francisco, CA: Jossey-Bass.

Collins, F. L., Sidhu, R., Lewis, N., \& Yeoh, B. S. (2014). Mobility and desire: International students and Asian regionalism in aspirational Singapore. Discourse: Studies in the Cultural Politics of Education, 35(5), 661-676.

Connelly, F. M., \& Clandinin, D. J. (1990). Stories of experience and narrative inquiry. Educational Researcher, 19(5), 2-14.

Corbin, J., \& Strauss, A. (2008). Basics of qualitative research: Techniques and procedures for developing grounded theory. ( $3^{\text {rd }}$ ed.). Thousand Oaks, CA: Sage.

Curtin, N., Stewart, A. J., \& Ostrove, J. M. (2013). Fostering academic self-concept: Advisor support and sense of belonging among international and domestic graduate students. American Educational Research Journal, 50(1), 108137.

Erkan, S., \& Walker, K. D. (2016). Fairness perceptions and experiences of Muslim university students in Canada. International Education Studies, 9(7), 7287.

Fries-Britt, S., George Mwangi, C. A. \& Peralta, A. M. (2014). The acculturation experiences of foreign-born students of color in physics. Journal of Student Affairs Research and Practice, 51(4), 459-471. 
Gardner, S. K. (2010). Contrasting the socialization experiences of doctoral students in high-and low-completing departments: A qualitative analysis of disciplinary contexts at one institution. The Journal of Higher Education, 81(1), 61-81.

Hall, S. (1997). Representation \& the media. Northampton, MA: Media Education Foundation.

Hanassab, S., \& Tidwell, R. (2002). International students in higher education: Identification of needs and implications for policy and practice. Journal of Studies in International Education, 6(4), 305-322.

Institute of International Education (IIE). (2016). Open doors fact sheet: Indonesia. Retrieved from https://www.iie.org/Research-and-Insights/OpenDoors/Fact-Sheets-and-Infographics/Leading-Places-of-Origin-FactSheets/2016.

Krippendorff, K. (2004). Content analysis: An introduction to its methodology (2nd ed.). Thousand Oaks, CA: Sage.

Lee, J. J. (2010). International students' experiences and attitudes at a U.S. host institution: Self-reports and future recommendations. Journal of Research in International Education, 9(1), 66-84.

Lee, J. J. \& Rice, C. (2007). Welcome to America? International student perceptions of discrimination. Higher Education, 53(3), 381-409.

Mamiseishvili, K. (2011). International student persistence in U.S. postsecondary institutions. Higher Education, 64(1), 1-17.

Matsumoto, D., \& Hwang, H. C. (2013). Assessing cross-cultural competence: A review of available tests. Journal of Cross-Cultural Psychology, 44(6), 849-873.

Merriam S. (2009). Qualitative research: A guide to design and implementation. San Francisco, CA: Jossey-Bass.

Miles, M. B., \& Huberman, A. M. (1994). Qualitative data analysis: An expanded sourcebook. ( $2^{\text {nd }}$ ed.). Thousand Oaks, CA: Sage Publications.

Mukminin, A. (2012). Acculturative experiences among Indonesian graduate students in U.S. higher education: Academic shock, adjustment, crisis, and resolution. Excellence in Higher Education, 3(1), 14-36.

Mukminin, A., \& McMahon, B. J. (2013). International graduate students' crosscultural academic engagement: Stories of Indonesian doctoral students on an American campus. The Qualitative Report, 18(35), 1-19.

Mukminin, A., Yanto, F., \& Yanto, H. (2013). Beyond the classroom: Religious stressors and adjustment among Indonesian Muslim graduate students in an American graduate school. Turkish Online Journal of Qualitative Inquiry, 4(2), 33-45.

Nguyen, D. J. (2016). Whose knowledge counts in international student assessments: Examining the AHELO epistemic community of economics experts. Tertiary Education and Management, 22(2), 121-133. 
Shahjahan, R. A., Morgan, C., \& Nguyen, D. J. (2015). 'Will I learn what I want to learn?' Usable representations, 'students' and OECD assessment production. Discourse: Studies in the Cultural Politics of Education, 36(5), 700-711.

Pan, J. Y., \& Wong, D. F. K. (2011). Acculturative stressors and acculturative strategies as predictors of negative affect among Chinese international students in Australia and Hong Kong: A cross-cultural comparative study. Academic Psychiatry, 35(6), 376-381.

Patton, M. Q. (2002). Qualitative research and evaluation methods. ( ${ }^{\text {rd }}$ ed.). Thousand Oaks, CA: Sage Publications Inc.

Poyrazli, S., \& Grahame, K. M. (2007). Barriers to adjustment: Needs of international students within a semi-urban campus community. Journal of Instructional Psychology, 34(1), 28-45.

Poyrazli, S., Arbona, C., Nora, A., McPherson, R., \& Pisecco, S. (2002). Relation between assertiveness, academic self-efficacy, and psychosocial adjustment among international graduate students. Journal of College Student Development, 43(5), 632-642.

Renn, K. A., Brazelton, G. B., \& Holmes, J. M. (2014). At the margins of internationalization: An analysis of journal articles on college student development, learning, and experiences, 1998-2011. Journal of College Student Development, 55(3), 278-294.

Schartner, A., \& Young, T. J. (2016). Towards an integrated conceptual model of international student adjustment and adaptation. European Journal of Higher Education, 6(4), 372-386.

Sherry, M., Thomas, P., \& Chui, W. H. (2010). International students: A vulnerable student population. Higher Education, 60(1), 33-46.

Su, M. \& Harrison, L. M. (2016). Being wholesaled: An investigation of Chinese international students' higher education experiences. Journal of International Students 26(4), 905-919.

Yan, K., \& Berliner, D. C. (2010). Chinese international students in the United States: Demographic trends, motivations, acculturation features and adjustment challenges. Asia Pacific Education Review, 12(2),173-184.

Yao, C. W. (2014). Being and belonging: A critical phenomenological study of undergraduate Chinese international students' sense of belonging in residence halls. (Doctoral dissertation). Michigan State University, East Lansing, MI.

Young, T. J., \& Schartner, A. (2014). The effects of cross-cultural communication education on international students' adjustment and adaptation. Journal of Multilingual and Multicultural Development, 35(6), 547-562.

Yu, B., \& Wright, E. (2016). Socio-cultural adaptation, academic adaptation and satisfaction of international higher degree research students in Australia. Tertiary Education and Management, 22(1), 49-64. 
Zhang, J., \& Goodson, P. (2011). Predictors of international students' psychosocial adjustment to life in the United States: A systematic review. International Journal of Intercultural Relations, 35(2), 139-162.

DAVID J. NGUYEN, PhD, is an Assistant Professor of Higher Education and Student Affairs in the Gladys W. and David H. Patton College of Education, Ohio University. His research interests center on access and equity within graduate education, the role of money in decision-making, and social class issues. Email: nguyend4@ohio.edu

JAY B. LARSON, PhD, specializes in internationalization in higher education. His major research interests are intercultural teaching and learning, institutional partnerships, and discourse in academic publishing. Email: jayblarson@gmail.com 